\title{
NOTE ON THE GAME COLOURING NUMBER OF POWERS OF GRAPHS
}

\author{
Stephan Dominique Andres
}

AND

\section{Andrea Theuser}

FernUniversität in Hagen

Fakultät für Mathematik und Informatik

IZ, Universitätsstr. 1, 58084 Hagen, Germany

e-mail: dominique.andres@fernuni-hagen.de

\begin{abstract}
We generalize the methods of Esperet and Zhu [6] providing an upper bound for the game colouring number of squares of graphs to obtain upper bounds for the game colouring number of $m$-th powers of graphs, $m \geq 3$, which rely on the maximum degree and the game colouring number of the underlying graph. Furthermore, we improve these bounds in case the underlying graph is a forest.
\end{abstract}

Keywords: game colouring number, marking game, graph power, game chromatic number, forest.

2010 Mathematics Subject Classification: 05C15, 91A43, $05 \mathrm{C} 05$.

\section{REFERENCES}

[1] G. Agnarsson and M.M. Halldórsson, Coloring powers of planar graphs, SIAM J. Discrete Math. 16 (2003) 651-662. doi: $10.1137 / \mathrm{S} 0895480100367950$

[2] T. Bartnicki, J. Grytczuk, H.A. Kierstead and X. Zhu, The map-coloring game, Amer. Math. Monthly 114 (2007) 793-803.

[3] H.L. Bodlaender, On the complexity of some coloring games, Internat. J. Found. Comput. Sci. 2 (1991) 133-147.

[4] T. Dinski and X. Zhu, A bound for the game chromatic number of graphs, Discrete Math. 196 (1999) 109-115. doi:10.1016/S0012-365X(98)00197-6 
[5] P. Erdős and A. Hajnal, On chromatic number of graphs and set-systems, Acta Math. Acad. Sci. Hungar. 17 (1966) 61-99.

doi:10.1007/BF02020444

[6] L. Esperet and X. Zhu, Game colouring of the square of graphs, Discrete Math. 309 (2009) 4514-4521. doi:10.1016/j.disc.2009.02.014

[7] U. Faigle, U. Kern, H. Kierstead and W.T. Trotter, On the game chromatic number of some classes of graphs, Ars Combin. 35 (1993) 143-150.

[8] M. Gardner, Mathematical games, Scientific American 244(4) (1981) 18-26.

[9] H.A. Kierstead, A simple competitive graph coloring algorithm, J. Combin. Theory Ser. B 78 (2000) 57-68. doi:10.1006/jctb.1999.1927

[10] H.A. Kierstead and W.T. Trotter, Planar graph coloring with an uncooperative partner, J. Graph Theory 18 (1994) 569-584. doi:10.1002/jgt.3190180605

[11] A. Theuser, Die spielchromatische Zahl der Potenz eines Graphen, Diploma Thesis (FernUniversität in Hagen, 2014), in German.

[12] J. Wu and X. Zhu, Lower bounds for the game colouring number of partial k-trees and planar graphs, Discrete Math. 308 (2008) 2637-2642. doi:10.1016/j.disc.2007.05.023

[13] D. Yang, Coloring games on squares of graphs, Discrete Math. 312 (2012) 14001406. doi:10.1016/j.disc.2012.01.004

[14] X. Zhu, The game coloring number of planar graphs, J. Combin. Theory Ser. B 75 (1999) 245-258. doi:10.1006/jctb.1998.1878

[15] X. Zhu, The game coloring number of pseudo partial k-trees, Discrete Math. 215 (2000) 245-262. doi:10.1016/S0012-365X(99)00237-X

[16] X. Zhu, Refined activation strategy for the marking game, J. Combin. Theory Ser. B $98(2008) 1-18$. doi:10.1016/j.jctb.2007.04.004 